\title{
Control social y construcción de hegemonía en la ciudad de Concepción (Chile), 1860-1900%
}

\author{
Social Control and Hegemony Building in the City \\ of Concepción (Chili), 1860-1900
}

\author{
Mauricio F. Rojas Gómez \\ y Marco A. León León \\ Universidad del Bío-Bío \\ y Universidad de Concepción (Chile)
}

Este trabajo estudia algunas transformaciones culturales de los sectores subalternos de la ciudad de Concepción (Chile) durante el siglo XIX. En especial se centra en aspectos relativos a la evolución y valoración de las ideas de trabajo y educación. Los ejes del estudio son: la dinámica del control social, ocurrida dentro de una estructura económica y política de tinte liberal y la construcción de hegemonía estatal.

PAlabras ClaVes: Control social; Hegemonía; Subalternos; Estado; Educación; Trabajo.

This paper studies some cultural transformations of subaltern sectors of the city of Concepcion during XIX century. It is specially centered in aspects concerned with evolution and valoration of work and education ideas. Two central aspects go through this article: the social control dynamic occurred within an economical and political structure of liberal and the state hegemony building.

KEYWORDS: Social control; Hegemony; Subaltern; State; Education; Work.

1 Esta investigación forma parte del proyecto FONDECYT N. ${ }^{\circ}$ 1110842, 2011-2014, Del «ser moral» a la conversión en «ser político». Estado, sociedad y construcción de ciudadanía en Concepción y Talcahuano (1860-1925). 


\section{Control social y hegemonía}

Desde hace un tiempo nos hemos interesado en el tema del control social y cómo éste se estructura por parte de las élites dirigentes del Estado chileno durante el siglo XIX. De esta forma hemos logrado distinguir en términos amplios dos estrategias de control por parte de los sectores dominantes: una centrada en la coerción, vía policía y aparato judicial; ${ }^{2}$ y la otra, en la persuasión. ${ }^{3}$ Para este último caso hemos destacado el rol que le cupo a la policía urbana de la ciudad de Concepción, creada el 2 de enero de 1860, cuya principal función era regular el aseo, ornato y salubridad de la ciudad. ${ }^{4} \mathrm{La}$ ampliación de la función policial, que hasta ese momento se componía de «vigilantes» diurnos y «serenos» nocturnos, se abocó directamente a transformar ciertas prácticas de la comunidad tendiendo a una mayor regulación de la vida cívica, con énfasis en el mejoramiento de las condiciones higiénicas y de salud.

Junto a la policía urbana se mantuvo la policía de «seguridad», la cual tenía por misión aplicar la coerción cuando las normas jurídicas se transgredían. Después de 1860 ambas policías coexistieron cumpliendo funciones complementarias. La policía de seguridad continuó con la aplicación de medidas punitivas sobre aquel sector de la población que no cumplía con las normativas aún vigentes del período colonial y/o con las incipientes leyes patrias que se fueron formulando durante los primeros años republicanos, las que se vieron uniformadas con el proceso de codificación hacia 1855 (Código Civil) y 1876 (Código Penal).

La legislación de la época de dominio hispano se mantuvo hasta bien adentrado el siglo XIX, como gran parte de la estructura estatal y social creada en esa etapa. Cabe recordar que las penas provenientes de aquella legislación - que incluso tenía raíces en la época medieval como fue el caso de las «Siete Partidas» (1265) — eran severas. No obstante, en la práctica, las sanciones no se aplicaban en todo su rigor gracias a la existencia del «arbitrio judicial» que era una facultad que la legislación indiana otorgaba al juez para morigerarlas, dependiendo de lo que éste considerase adecuado. Muchas de las normas que se dictaron tenían relación con las conductas que se querían modificar en los transgresores. Para el caso de los

2 Rojas Gómez, 2008a, 77-99.

3 Rojas Gómez, 44/2, 2011, 443-465.

4 Archivo Nacional de Chile (ANCh), Boletín de las leyes y decretos del Gobierno: 1860, Libro XXVIII., Ordenanza Municipal de Concepción, Santiago, 2 de enero de 1860. 
delitos de robo, hurto y abigeato era castigo común la fijación territorial, que obligaba a los sujetos a quedar bajo la supervisión de una persona destacada de la comunidad o bien bajo la vigilancia de algún inspector, subdelegado o cualquiera otra autoridad que señalase el juez. ${ }^{5}$ Esta sanción se dotaba de sentido en cuanto el tipo humano de la provincia de Concepción respondía a la definición de un sujeto de frontera el cual se caracterizaba por su independencia, manifestada en su desarraigo espacial y en las prácticas económicas de carácter autárquico y esporádico. En el plano masculino, frecuentemente era un gañán que trabajaba cuando lo necesitaba y que se desplazaba por amplios márgenes geográficos. ${ }^{6}$

Enlazada con la fijación territorial se encontraba la compulsión laboral. Esta pena complementaba la primera pues no sólo se esperaba que el sujeto infractor residiera en un espacio determinado que le permitiese al Estado poder ejercer control sobre él, sino también se pretendía transformar sus hábitos de vida y regular su actividad laboral. ${ }^{7}$ Lo que ambas penas buscaban era hacer visible al infractor, situarlo para poder localizarlo. En resumen, convertir a un sujeto de frontera en un sujeto controlado.

El trabajo sistemático y regulado era un aspecto ajeno a los comportamientos de amplios sectores de la población de Concepción y sus territorios aledaños. La compulsión laboral daba cuenta de que un estilo de vida centrado en el trabajo regulado era ajeno a la visión que tenía de él gran parte de la sociedad civil. Era un objetivo del naciente Estado-nación chileno poder controlar la población, de ahí el esfuerzo de disciplinar conductas que tendieran a la dispersión y la laxitud en los individuos. En ese contexto el trabajo compulsivo era una fórmula en torno a la cual se pretendía configurar un «sujeto moral» que respondiese a los nuevos pilares sobre los cuales lograr el orden y el progreso.

El trabajo regulado no era propio de los comportamientos de los sectores subalternos de la población penquista. Este hecho obliga a retrotraer nuestra mirada hacia el precedente histórico que configuraba la idea de Estado bajo el dominio colonial de la dinastía borbónica en América. Como afirma Michael Scardaville, el Estado Borbón era intervencionista, materialista y centralizado. La racionalidad en la administración gubernativa pretendía el crecimiento económico y material; por lo mismo, las refor-

5 Fernández Undurraga, 1989, 11.

6 Araya, 1999, 23-66. Salazar, 2006, 20-25.

7 Rojas Gómez, 26, 2007, 41-42. 
mas institucionales se articulaban en la prosecución de dicho objetivo. Según el criterio de la Corona, mantener una sociedad ordenada bajo una estructura legal efectiva permitiría forjar una sociedad estable y, por ende, conseguir el tan anhelado crecimiento económico. ${ }^{8}$ Pero las acciones de las autoridades chilenas durante los primeros años de la etapa republicana dan cuenta que la población no había asimilado los principios rectores que los Borbones quisieron imponer. Todavía no había una organización social homogénea ni un orden centralizado que conllevase al tan anhelado progreso material. De hecho, la inexistencia de estos postulados en la cultura de la población obligó a los gobiernos conservadores a tratar de imponer una estructura social y política que hoy conocemos como «orden portaliano».

Queda en evidencia, entonces, que bajo el régimen colonial borbónico hubo en Chile, y particularmente en Concepción, lo que Ranajit Guha ha denominado un sistema de dominación sin hegemonía. ${ }^{9}$ Es decir, el Estado Borbón no logró la asimilación de la sociedad a los postulados que sustentaba, más bien sólo ejerció un dominio pero no logró construir hegemonía. Ante esta carencia presentada por el Estado español, las elites chilenas decimonónicas debieron abocarse a la tarea de construcción de hegemonía. Para ello era necesario ordenar la sociedad (controlarla) y, posteriormente, incorporar en ella los postulados que consideraban adecuados para el establecimiento de un sistema de gobierno que pudiese lograr el progreso material.

Siguiendo el planteamiento de Antonio Gramsci, la idea de hegemonía se ha comprendido como «la capacidad que tiene un determinado grupo social de dirección política, espiritual y moral». ${ }^{10}$ Ello implica ir más allá de los aspectos formales en las relaciones al interior de un Estado, involucra también una concepción de mundo. De manera relativamente reciente, los estudios subalternos han ido proporcionando luces respecto a la conceptualización de la idea de hegemonía. Ranajit Guha, uno de los fundadores del grupo de Subaltern Studies, entiende la hegemonía como «aquel consenso construido por la disciplina de la Historia, cuya función es narrar la unidad de la gente alrededor del concepto del Estado». ${ }^{11}$ La relación que establece entre hegemonía e historiografía se contextualiza en la India del siglo XIX. Considera que en las primeras décadas de ese siglo se

8 Scardaville, 2000, 4.

9 Guha, 1997, xii.

10 Orozco, 2005, 3.

11 Rodríguez, 1998, 4. 
requería necesariamente la construcción de una visión autónoma del pasado colonial indio, para ello era preciso apropiarse de ese pasado en el afán de construir hegemonía. De ahí que sostenga que la autonomía de la historiografía no era sólo una cuestión de lenguaje sino también una cuestión de poder. Los discursos colonialistas habían llevado a cabo un proceso de apropiación del pasado por razones de Estado y para ello debieron realizar una doble función: construir un tiempo y matar un tiempo, según los intereses codiciados por algunos. ${ }^{12}$ A ello habría que agregar que la hegemonía no significa la desaparición o destrucción de la diferencia, sino la construcción de la voluntad común por medio de la diferencia. ${ }^{13}$

La evolución de los planteamientos teóricos en torno a la idea de hegemonía nos permite abordar las transformaciones culturales de la población no sólo como la resultante de una relación vertical de poder procedente desde el Estado, sino también hace posible incluir la participación de la población subalterna en la construcción de hegemonía. Este proceso no estuvo exento de tensiones y rechazos por parte de la comunidad, pero dentro de un proceso de «negociación» con los grupos dominantes una vez que ciertos postulados provenientes de éstos pasaron a su repertorio cultural.

\section{El sentido del trabajo colonial}

La hegemonía estatal, expresada a través de diversas normativas y directrices, no sólo se estableció mediante la acción coercitiva en su intento de imponer criterios únicos y excluyentes. Si bien la coerción se utilizó como mecanismo de control social, coexistió con otro, a nuestro parecer, aún más efectivo: el control social por la persuasión o consenso. Ello nos lleva a la ampliación del horizonte de intelección respecto al tema en cuestión, ya que nos obliga a penetrar en el difícil campo de los contenidos de conciencia de los actores colectivos.

En el afán de hacer objetivable el proceso descrito, hemos considerado oportuno estudiar el itinerario de la idea de trabajo en los sectores subalternos durante el siglo XIX, con el fin de apreciar, en la variación de sus significados, el nivel de incorporación de los postulados elitarios a los contenidos de conciencia subalterna. Ello nos permitirá ir esclareciendo el

12 Guha, 1997, 193-194.

13 Hall, 1991, 58. 
proceso de construcción de hegemonía al cual hemos hecho referencia, ya que sostenemos que la hegemonía es una concesión de la sociedad civil al Estado, dentro del Estado.

El historiador Gabriel Salazar, en su trabajo «Labradores, peones y proletarios», establece que:

\begin{abstract}
Antes que el sector industrial deviniera en el principal empleador urbano - antes de 1860, más o menos-, al peonaje de ciudad se le enganchaba para realizar cortos trabajos a jornal en obras públicas, o en forma permanente, con un salario nominal, para el servicio doméstico en las casas patricias o para el Ejército...Para los patrones de esos años no existía ninguna diferencia digna de mención entre el peón-gañán; el sirviente doméstico, el soldado-recluta, el vagabundo, el regatón y el presidiario. Todos ellos tenían el mismo status social y se hallaban sometidos al mismo régimen de enganche y de salario, represivo y punitivo. ${ }^{14}$
\end{abstract}

Lo descrito por Gabriel Salazar manifiesta un concepto del trabajo que respondía a necesidades puntuales de una elite que regía un Estado en formación. De hecho, los grandes «empleadores» dentro del sistema indicado eran las elites gubernativas que bien podían ocupar compulsivamente a un hombre o una mujer para tareas tan disímiles como recluta forzado o la servidumbre en una «casa decente». El símbolo por antonomasia de lo señalado fueron los vagos quienes, incluso, se vieron obligados a trabajar junto a presos en faenas públicas. Esta situación fue cambiando cuando el trabajo asalariado del peonaje libre se fue imponiendo sobre el de los presidiarios, especialmente con el advenimiento de las inversiones reproductivas por parte de los grandes mercaderes. A ello hay que sumar la legitimación de los métodos patronales del empresariado extranjero y el que las obras fuesen ejecutadas por compañías formales en vez de supervisores municipales o eclesiásticos. ${ }^{15}$

Si bien el trabajo asalariado se venía dando desde la década de 1820 , no es menos cierto que el dinero pagado por los patrones chilenos (incluyendo el Estado) era insuficiente para satisfacer las necesidades de vida de los trabajadores. ${ }^{16}$ De ahí que Gabriel Salazar considere que la mentalidad económica de los empresarios extranjeros y las nuevas inversiones realizadas, entre las que se destaca la construcción de vías férreas, hayan favorecido a las transformaciones ocurridas en materias laborales. Ello concuer-

14 Salazar, 2000, 239.

15 Ibídem, 241-245.

16 Ibídem, 242. 
da con lo afirmado por Luis Ortega, quien considera que las repercusiones de la construcción y operación del ferrocarril, tanto en la zona central de Chile como en particular en Concepción y Chillán, provocaron un crecimiento de la población urbana. ${ }^{17}$

El proceso acelerado de concentración de la población urbana y la presencia de inversiones lideradas por el empresariado extranjero, fue un factor gravitante para la transformación de los grupos subalternos penquistas. La transmutación cultural de la población subalterna de mediados de siglo XIX se produjo en un contexto urbano. Fue resultado de un proceso previo de cambios sociales que se llevaron a cabo con mayor nitidez a partir de la década de 1860, como consecuencia de la adopción de la estrategia liberal de desarrollo. En esta etapa, junto a una nueva forma de pensar la economía, se advierten una serie de discursos que colaboraron a reconsiderar tanto la estructura estatal como la participación en los procesos políticos de aquellos sectores sociales que hasta ese momento habían sido excluidos.

La adopción del liberalismo como estrategia de desarrollo tuvo como correlato la resignificación de la «economía moral» de la población subalterna. Esto, a su vez, se encuentra vinculado a dos aspectos: a) el autoaprendizaje político de aquel sector mayoritario de la comunidad $y, b)$ la creación de hegemonía, que posibilitó la gobernabilidad del Estado chileno.

Para tratar de entender la transformación cultural ocurrida con la adopción del liberalismo es pertinente apreciar de qué manera se conformaba la economía colonial. Según nos informa Ruggiero Romano, durante ese período la población fue organizada en formas de trabajo o laborales, caracterizada por ser de tipo forzado. ${ }^{18}$ Dicho rasgo explicaría que el trabajo haya sido entendido - tanto por las élites por la población subalterna- como una imposición, de la cual estos últimos no recibían los principales beneficios puesto que las riquezas iban a engrosar las arcas de reducidos grupos dominantes.

A ello hay que agregar que durante los siglos coloniales se produjo una clara desmonetización de la economía americana, ${ }^{19}$ la cual todavía era una situación de malestar en Concepción hacia mediados del siglo XIX, provocando quejas como la siguiente:

17 Ortega, 2005, 134-135.

18 Romano, 2004, 395-396

19 Ibídem, 399. 
El puerto de Talcahuano y el comercio de Concepción en jeneral, esperimenta hace ya algún tiempo una paralización casi total...Para nosotros, en América hai muchas razones que contribuyen a estas paralizaciones más o menos largas de las transacciones mercantiles: lo limitado de nuestro comercio, de nuestros retornos, de nuestros capitales y de nuestros medios de competencia con mercados más poderosos... La pobreza, el atraso, la escasez de estímulos es la gran plaga americana ${ }^{20}(\mathrm{sic})$.

A fines del siglo XVIII el dinero en el Obispado de Concepción era casi inexistente, lo que redundaba en una economía mayoritariamente de subsistencia. Para ese período aún no se advierte el desarrollo de una economía monetaria, por lo que es dable indicar que este tipo de economía se desarrolla durante el siglo XIX. La carencia de dinero trajo aparejado el intercambio de bienes entre la población, en especial aquellos productos ligados a las labores agrícolas. Esta característica de la economía provocó una pauperización notable de la población, aspecto del cual ha dejado registro el soldado cronista Vicente Carvallo Goyeneche:

En este obispado no se trabaja en el laboreo de minas, i todos sus habitantes son labradores, i es la única ocupación que pueden tener. Con ella no les falta que comer; pero como es única no hai entretenimiento para toda clase de personas i así por esta razón como por las jentes del campo, no tienen arbitrio para vender los pollos, huevos y demás jéneros menudos; pasan una vida muy miserable. ${ }^{21}$

Esta descripción para el Obispado de Concepción no era diferente a lo que ocurría en el resto del país. Incluso quienes podrían estar considerados en una mejor situación económica dentro del campesinado, como fue el caso de los inquilinos, no se diferenciaban demasiado del resto de la población rural. El estado de pobreza en que se encontraban no proporcionaba incentivos al trabajo, lo que finalmente redundó en el daño a la agricultura. Ya en los albores del siglo XIX, el secretario del Consulado, José Cos Iriberri, en la redacción de la «Memoria» del año1799 da cuenta de la permanencia de esta característica de la economía colonial:

Proporcionemos propiedad al pobre colono o inquilino que habita las estancias que no puede llamar suyos ni aun los cuatros palos de que forma su miserable choza y que por la infeliz constitución de las cosas se puede decir que está sujeto a casi todas las servidumbres del régimen feudal, sin gozar ninguna de sus ventajas. ${ }^{22}$

20 ANCh, El Correo del Sur, Concepción, 18 de noviembre de 1852, 2.

21 Carvallo Goyeneche, 1876, 95.

22 Cos Iriberri, Memoria de 1799, en: Cruchaga, 1929, 264. Villalobos, 2009, 181. 
Resulta evidente que la economía monetaria, con su respectiva valoración del salario y la disciplina laboral, no formaban parte de la cultura de los sujetos de la sociedad colonial. Esta es una de las razones que irán configurando la concepción del trabajo en la zona central de Chile, al menos hasta la primera mitad del siglo XIX.

No obstante, se advierten en las primeras décadas del mencionado siglo ciertas señales que expresan cambios culturales en la población subalterna: en un trabajo anterior, acerca del abigeato en el siglo XIX, hemos concluido que los abigeos, si bien pertenecían por jerarquía social a los sectores subalternos, en estricto rigor gozaban de una condición diferente a los demás miembros de su sector. La especulación en el precio de venta de los animales, la búsqueda de mejores mercados y, sobre todo, la utilización del dinero como medio de intercambio, trajeron como consecuencia que estos sujetos se fueran acercando paulatinamente a la lógica comercial de la economía monetaria. ${ }^{23}$ Nos parece que ellos constituyeron un eslabón dentro de la paulatina transformación, y posterior incorporación, de los sujetos subalternos a la estructura económica liberal.

Según el «Anuario Estadístico», el delito de mayor ocurrencia hasta 1860 fue el de abigeato. Esto demuestra, por una parte, que dicha conducta delictiva estaba bastante extendida; y, por otra, que era una transgresión que se perseguía con mucho celo. El vínculo entre estas dos posibilidades se entiende al reconocer el incremento del valor económico que ciertas especies fueron adquiriendo durante el siglo, en este caso, el ganado. Aquello posibilitó que algunas prácticas de la población, que habían sido legitimadas por la costumbre, en aquel período se incorporaran al repertorio de acciones consideradas como abigeato.

Después de las luchas de independencia hubo cambios en el mercado y el precio del ganado llegando a cifras que causaban fuertes críticas a mediados de siglo:

En los precios corrientes de los productos de las provincias que insertamos en el número de hoi, son notables los de los animales vacunos cuya demanda para el norte ha hecho subir su valor común notablemente...en las legumbres y otros productos se nota escasez...Concepción, por lo que respecta a manutención, no tendrá luego nada que envidiar a Valparaíso o Copiapó en carestía. ${ }^{24}$

23 Rojas Gómez, 26, 2007, 37.

24 ANCh, El Correo del Sur, Concepción, 18 de noviembre de 1852, 2. 
La conformación de la propiedad colonial en la zona de Concepción se caracterizó por el predominio del minifundio, al menos durante las tres primeras décadas del siglo XIX. Con el correr del siglo esto se fue modificando tendiendo hacia una creciente concentración de tierras. El historiador Marcello Carmagnani considera que se dieron las condiciones necesarias para la progresiva constitución de una gran propiedad que dominó a la pequeña y a la masa de mano de obra. ${ }^{25}$ Correlato de lo anterior fue una nueva concepción de la propiedad privada que se evidenció en el mayor rigor al momento de sancionar delitos que atentasen contra ella. La propiedad privada se yergue como un bien jurídicamente tutelado lo que explica que los índices de robos, hurtos y abigeato hayan sido los más altos dentro de la estadística criminal.

Las transformaciones estructurales de tipo económico, que comenzaron a evidenciarse en el primer tercio del siglo XIX, estuvieron aparejadas con transformaciones culturales. Es difícil precisar que fue primero, si las modificaciones ocurridas en el intercambio comercial o las transformaciones culturales, lo que sí se advierte son las nuevas formas de relación entre los grupos dominantes y los subalternos. Una de estas manifestaciones fueron las tensiones sociales que se produjeron cuando las elites comenzaron a valorar aspectos que tradicionalmente no lo habían sido, al menos con tanta acuciosidad. La propiedad privada comenzó a verse como un bien valioso el cual debía protegerse; por lo mismo, conductas que durante el período colonial fueron aceptadas socialmente, en la etapa republicana comenzaron a ser criminalizadas (por ejemplo, la práctica del «aparaguayamiento»). ${ }^{26} \mathrm{~A}$ esta revaloración de la propiedad privada se sumaron otros bienes de carácter intangible a los cuales las elites dirigentes también les confirieron un estatus de privilegio, tales como la honra, el orden y el control. ${ }^{27}$

La historiografía chilena ha analizado desde diversas perspectivas unas de las primeras medidas de carácter puramente económico del gobierno chileno como fueron el «Decreto de Libre Comercio» de 1811 y el posterior «Reglamento de Libre Comercio» de $1813 .{ }^{28}$ Recientemente, historiadores como Eduardo Cavieres, ${ }^{29}$ Gabriel Salazar y Julio Pinto, han

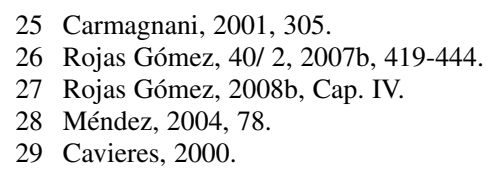


subrayado las implicancias que tuvieron tales decisiones en cuanto a la apertura comercial de Chile al exterior. Como manifestación de ello han señalado que, entre 1820 y 1848, el flujo comercial entre nuestro país y Gran Bretaña se incrementó 36 veces en lo referente a exportaciones y 19 veces para las importaciones..$^{30}$ Destacamos este hecho pues implica una nueva mirada a las relaciones comerciales, al rol de los mercados, a las funciones del Estado y, paralelamente, va cimentando las bases de una nueva conformación de las estructuras sociales de la economía.

\section{Estructuras sociales de la economía: «economía doméstica» y «espíritu de cálculo»}

El sociólogo Pierre Bourdieu sostiene que la ciencia económica se caracteriza por tener una visión «ahistórica» debido a su ilusión de universalidad tanto de las categorías como de los conceptos que ha utilizado como dato. Por ello considera necesario reconstruir, por una parte, el origen de las disposiciones económicas del agente económico como sujeto, es decir, sus gustos, necesidades, propensiones y aptitudes (entre ellas, el trabajo); y, por otra, la génesis del campo económico en sí, a saber, confeccionar la historia del proceso de diferenciación y autonomización del campo económico. En este estudio, nos centraremos en la primera parte de lo sugerido por Bourdieu con el fin de historiar la idea de «trabajo» en el Concepción del siglo XIX y, de esta manera, poder objetivar las transformaciones ocurridas en la cultura subalterna.

Un aspecto a revelar es el cambio de centro en las relaciones económicas. En general, la base de la estructura social de la economía colonial americana era de tipo doméstica, donde las relaciones personales adquirían preponderancia determinante. En las elites económicas destaca la presencia de redes familiares vinculadas a las esferas administrativas y militares, lo cual configuraba una imbricada trama de negocios y acción política donde las conveniencias mutuas entre los distintos actores era el sustrato que las contenía. En tanto, las familias de los sectores subalternos (indígenas, inquilinos, peones, sirvientas, entre otros) estaban vinculadas al grupo dominante por el trabajo que debían realizar para ellos, casi en ausencia de salario. Tanto la ciudad como la provincia de Concepción compartían este

30 Salazar y Pinto, 2002, 19-20. 
rasgo. Por ello, ante la prácticamente inexistente economía monetaria, hubo una primacía de la economía doméstica o de subsistencia. ${ }^{31}$ Las relaciones de dependencia definieron este tipo de estructura social de la economía: primero, entre los grupos dominantes y los subalternos, cuando se trataba de la subordinación directa de estos últimos a los primeros; segundo, en el caso del ámbito exclusivo de los minifundistas, la constitución de redes familiares en torno a un tipo de economía que podríamos calificar de «natural», para diferenciarla de la economía monetaria, determinada por el flujo de dinero.

Un denominador común en las diferentes capas sociales del período colonial chileno fue la escasez de dinero. Aunque las elites poseían extensiones de terreno que determinaban su prestigio social y riqueza, ello no significaba que gozasen de enormes fortunas en metálico. Esta situación irá variando a partir de las primeras décadas del siglo XIX cuando se produce un cambio de signo en las estructuras sociales de la economía apareciendo lo que se ha llamado el espíritu de cálculo.

Los rasgos predominantes de ambas estructuras sociales de la economía, la economía doméstica y el espíritu de cálculo, han sido sintetizados por P. Bourdieu de la siguiente manera:

El espíritu de cálculo...se impone poco a poco, en todos los ámbitos de la práctica, contra la lógica de la economía doméstica, fundada sobre la represión o, mejor, la negación del cálculo: negarse a calcular en los intercambios familiares es negarse a obedecer el principio de economía, como aptitud y propensión a «economizar» o «hacer economías» (de esfuerzo, de pena, y luego de trabajo, de tiempo, de dinero, etc.). ${ }^{32}$

El «espíritu de cálculo» resultaba extraño en una economía donde primaban las relaciones personales y de dependencia. En el caso de los grupos desfavorecidos de la sociedad penquista (mayoría de la población) significaba romper con aspectos basales de la conformación social, ya que uno de los elementos propios de la constitución de sus relaciones interpersonales era la solidaridad. ${ }^{33}$ En esta nueva comprensión de las relaciones económicas los objetivos pretendidos sufrieron una inversión epistemológica

31 Romano, 2004, 414-415.

32 Bourdieu, 2005, 19-20.

33 Un episodio descrito por Gabriel Salazar nos ilustra al respecto: Todos los campesinos pobres que auxiliaron a Rosaria Araya en el día de su culpa y llanto cumplieron, pues, lo que habían prometido: criar a sus hijos con la ayuda de todos. Fueron, por eso, hijos «huachos», y a la vez, hijos del pueblo. Salazar, 2006, 18. 
respecto a la economía doméstica, pues la ganancia y el cálculo de los beneficios reportados serán ahora el norte de su lógica. Manifestación de lo dicho es que incluso un personaje como el abigeo no escatimó esfuerzos en entrar en contacto comercial con los grupos dominantes con tal de obtener pingües ganancias. ${ }^{34}$

En este tránsito de una economía doméstica a una de cálculo necesariamente debemos considerar factores heterónomos. Werner Sombart, al estudiar el afán de lucro ligado a las actividades económicas, identifica al menos dos etapas de desarrollo del espíritu capitalista: el capitalismo de viejo y nuevo estilo. Este último, posterior a la revolución industrial, se caracteriza por el afán de lucro, la competencia a ultranza y la despersonalización en las relaciones comerciales. ${ }^{35}$ De esta manera, el nuevo capital mercantil europeo se convierte en el agente impulsor de las transformaciones ocurridas en los nacientes Estados americanos. Este nuevo capital comercial estaba preparado para ingresar a los mercados de los antiguos territorios hispánicos desde antes de 1800, por ello a la menor señal de ruptura con España irrumpieron en los territorios americanos. Como ejemplo de lo dicho podemos mencionar que las exportaciones de Gran Bretaña a América del Sur llegaron a contar entre el $25 \%$ al $40 \%$ del total de sus exportaciones, por lo que se concluye que el tráfico comercial con estos territorios resultaron de suyo beneficiosos para aquel Estado. ${ }^{36}$

La presencia del comercio británico en Chile se dejó sentir con fuerza en la época posterior a la Independencia. Las élites criollas adoptaron rápidamente los postulados de los comerciantes ingleses, en particular dos aspectos que resultaron estratégicos: a) la «modernización industrial» del país, y b) el «patrocinio occidental» del librecambismo, que fue enarbolado por los gobiernos chilenos durante el siglo XIX. ${ }^{37}$ En este nuevo escenario económico y político, las elites requerían llevar a cabo un proceso de transformaciones estructurales en la naciente República. Cambios que debían, necesariamente, involucrar al conjunto de la población que hasta ese momento no había sido partícipe de las decisiones que se estaban tomando.

34 Hacia 1833 el ingreso promedio anual del 87,4 \% de la población en la provincia de Concepción era de $\$ 25,6 .-$. A fines de 1852, un par de bueyes gordos costaba $\$ 25 .-$, unos en estado regular, \$22.-, un par de novillos, \$20.-, y un par de vacas. \$17.- Esto nos permite inferir que un abigeo podía lograr el salario de un año con una venta de bueyes. Rojas Gómez, 2006, 37. ANCh, El Correo del Sur, Concepción, 25 de diciembre de 1852, 7.

35 Sombart, 1972, 176-194.

36 Salazar, 2009, 81-85.

37 Ibídem. 
A comienzos del siglo XIX las relaciones laborales entre los grupos dominantes y subalternos se distinguían por el predominio de los vínculos de dependencia y el escaso flujo monetario. Estos aspectos requerían ser modificados en el nuevo estilo de hacer negocios, ya que entorpecían el desarrollo del modelo liberal de la economía. Implantar un sistema económico de este tipo requería incrementar el flujo monetario existente como, asimismo, aumentar la productividad de los campos y las industrias. Ello no sería factible de llevar a efecto sin la participación de los sujetos subalternos y, para lograr esto, había que establecer nuevas formas de relación con los mismos.

Este «nuevo trato» social requería previamente establecer dominio sobre la población, lo que se manifiesta desde los albores de la vida independiente a través de la elaboración de leyes patrias relativas a la administración de justicia como fueron el «Reglamento Provisorio de 1818» y los Reglamentos de Administración de Justicia de 1824 y 1837. Como ya hemos dicho, esta legislación pretendía la modificación de conductas subalternas con el fin de «civilizar» sus costumbres, lo que en la práctica significaba organizar la vida privada y pública de los sujetos según los cánones de las elites, de ahí que en su artículo 26 el «Reglamento de Policía» de la ciudad de Concepción indicase:

No se permitirán chinganas, ramadas, juegos de bola u otros que se acostumbran el bajo pueblo, ruedas de fortuna, rifas ni juegos de caballos, sin previa licencia del gobierno local con designación de sitio y hora, y sin que se pueda jugar prendas, ropas ni cosechas futuras. ${ }^{38}$

En agosto de 1885, con la dictación de la «Ordenanza de Policía para la ciudad de Concepción», se vuelven a estipular algunas medidas semejantes a las descritas, esto es: prohibición del desplazamiento de ebrios por las calles que molesten a los transeúntes; impedimento para usar disfraces; prohibición de portar armas de fuego o blancas, entre otras. Sin embargo, ya no aparecen mencionadas conductas estipuladas en el artículo 26 del Reglamento de Policía de 1834 como eran la prohibición de chinganas, ramadas, rifas o juegos de bola. Ello evidencia el acatamiento de la población subalterna a las medidas impuestas por los grupos dirigentes y la efectividad de las medidas coercitivas llevadas a cabo por la policía.

38 ANCh, El faro de Bío-Bío, Reglamento de Policía de Concepción, Concepción, miércoles 29 de enero de 1834. 
Otro aspecto a destacar de manera relevante es el hecho que ninguna de las medidas presentes en la Ordenanza de 1885 establecía penas relacionadas con la compulsión laboral y la fijación territorial, como puede verse en algunos artículos que mencionamos a continuación:

Art. $2^{\circ}$ Los que en las calles i lugares públicos suscitaren pendencias, alteraren la tranquilidad pública [...] sufrirán una pena de uno a quince días de prisión conmutable en multa de uno a quince pesos.

Art. $3^{\circ}$ Cualquiera persona que en las calles o lugares públicos usare disfraces será penado con multa de cuatro pesos, sin perjuicio de ser juzgado con arreglo a las leyes comunes $[\ldots]$

Art. $6^{\circ}$ Es prohibido andar a caballo por las aceras i galopar por las calles, bajo multa de cincuenta centavos a un peso, $i$ de uno a dos pesos en caso de reincidencia $[\ldots] . .^{39}$

Las sanciones contenidas en los diversos artículos de la Ordenanza básicamente se remitían al pago de multas. Si se observa con detención, el artículo 2 parece establecer una relación directamente proporcional entre un día de prisión con el valor de un peso, lo que implica la equivalencia y regulación de las transgresiones sociales en términos monetarios.

Los estudiosos del delito convienen en aceptar la idea que los castigos se aplican para proteger aquellos aspectos que, en términos generales, las sociedades estiman valiosos. Para las élites chilenas de los primeros años de vida republicana era necesario establecer dominio sobre el colectivo social. En ese afán, algunos de sus postulados no concordaron con los comportamientos de los sectores subalternos, lo que explica la aplicación de penas que contemplaban la compulsión laboral y la fijación territorial. A su vez, una lectura inversa de estas sanciones nos permite conocer la valoración de ciertas conductas de los grupos subordinados, en este caso se observa el aprecio que tenían por la libertad de desplazamiento y la no sujeción permanente a un otro. A fines de la década de 1880 la estima hacia estas prácticas ya no aparece con el acento de comienzos de siglo, siendo reemplazada por el valor monetario. En este traslado de consideraciones de valor, el dinero era visto como un bien apreciado por la población dejando al descubierto transformaciones estructurales que afectarán la mentalidad económica subalterna. En este caso, a lo menos, en dos aspectos: a) la efectiva apropiación de un bien esencial de la cultura liberal,

39 ANCh, Boletín de las Leyes y Decretos del Gobierno, 1885, Libro LIV, n. ${ }^{\circ}$ 7, «Ordenanza de policía para la ciudad de Concepción», Santiago 10 de agosto de 1885 . 
como es el dinero; ${ }^{40}$ y b) la posibilidad que estos grupos tengan acceso a la moneda como medio de intercambio y transacción, por ejemplo en el pago de una multa.

La transformación cultural ocurrida en la población subalterna durante el siglo XIX no sólo puede ser explicada a través del control social punitivo estatal. Más aún, una explicación semejante sería insuficiente para entender el proceso de apropiación subalterna de valores y prácticas emanadas de las elites dirigentes. Para ello, sugerimos incorporar al análisis el concepto de economía moral, acuñado por el historiador inglés E. P. Thompson. Esta herramienta teórica nos permitirá configurar otro aspecto a considerar como es la construcción de hegemonía, íntimamente ligado a las relaciones sociales y su vinculación con el Estado.

\section{Economía moral y construcción de hegemonía}

En páginas precedentes hemos hecho alusión a componentes centrales de la idea de hegemonía, dando a entender que ella es una expresión de dominación que abarca fuerzas políticas, sociales y culturales. En tanto el dominio más bien se circunscribe a formas políticas directas donde se privilegian las prácticas coercitivas. Durante la primera mitad del siglo XIX, la sociedad penquista soportó un énfasis centrado en mecanismos de este último tipo cuya influencia provenía de las directrices estatales emanadas del pensamiento «portaliano» ${ }^{41}$ y su concepción de la legalidad..$^{42}$

En la ciudad de Concepción, a partir del mes de enero de 1860, se comienza a implementar el mecanismo de control social por el consenso mediante la creación de la policía urbana y la respectiva reestructuración de

40 Puesto que gran parte de la economía capitalista se resuelve en una serie de acuerdos comerciales sobre servicios recíprocos expresables en dinero (compra de medios de producción, venta de productos acabados, contratación de mano de obra, etc.), y puesto que todo el comercio capitalista se reduce en último término a una simple suma de dinero, es natural que la mentalidad calculadora, como he dado en llamarla, constituya una pieza esencial de la maquinaria capitalista. Sombart, $1972,137$.

41 Se denomina así al ideario político planteado por el Ministro Diego Portales Palazuelos (1793-1837). El llamado «período portaliano», iniciado en 1830, corresponde a una serie de gobiernos conservadores donde predominaban las ideas de orden y obediencia de la sociedad civil respecto a la autoridad estatal.

42 Un ejemplo se puede apreciar en la siguiente frase de Diego Portales: Sin que ella sea buena, vemos como perdidos los trabajos del gobierno, e inútiles sus deseos de mejorar las costumbres y de conservar las leyes en su vigor... Si los jueces y tribunales no son íntegros, si no son animados por un odio santo al crimen, es segura la impunidad de los criminales... Portales, 1832, en: León, 1996, 43. 
los cuerpos policiales. Esta acción tenía como meta la modificación de los comportamientos de la vida cotidiana de la población, lo que no tardó en dar frutos. De este modo, en la etapa de predominio liberal ${ }^{43}$ (segunda mitad del siglo XIX) se complementaron las dos estrategias de control social: la coercitiva (policía de seguridad, tribunales) y la persuasiva, basada en el consenso, cuya labor fundamental estuvo dada por la policía urbana.

El éxito del establecimiento de la hegemonía oligárquica liberal estuvo basado principalmente en el control social por el consenso. Con el correr del siglo, y de manera paulatina, se produjo un cambio en la cultura subalterna que concluyó con la apropiación de una visión del mundo de tipo capitalista, donde el beneficio económico era central. El correlato de aquello fue la consiguiente valoración de aspectos que a comienzos del siglo XIX no formaban parte del repertorio de valores arraigados en los sectores populares tales como las ganancias individuales y la propiedad privada, que ahora se convertirán en bienes jurídicamente tutelados.

E. P. Thompson al definir la idea de economía moral, planteó que ésta se sustentaba en una visión tradicional de la población que entendía que había normas, obligaciones sociales y funciones económicas propias de cada sector de la sociedad. Afirma que si bien esta economía moral no podía definirse como «política» en un sentido progresista, tampoco podía ser catalogada como «apolítica», pues suponía nociones del bien público por parte de los sectores subalternos. ${ }^{44}$ En una posterior discusión del concepto (1991) agrega que el ascenso de la sociedad de mercado, «trajo consigo horrores indiscutibles», pero que «también trajo un énfasis en la libertad de elección individual, el derecho a mejorar la propia posición, con el tiempo la oportunidad de participar en política».45

Cuando las elites penquistas, en el contexto de la estrategia liberal de desarrollo, quisieron transformar vía el control social por el consenso a las «clases peligrosas» en «clases trabajadoras», sin proponérselo tuvieron como resultado la modificación de la economía moral subalterna. Un ejemplo de ello es que, al incorporarse a la estructura económica capitalista, las demandas de la población se dirigieron a la protección de sus propiedades y a la seguridad que debía otorgarles el Estado. Las antiguas nociones acerca de la propiedad privada, un tanto laxas, cambiaron en el último tercio de

43 Heise, 2007, 71-84.

44 Thompson, 2000, 216-217.

45 Ibídem. 
la centuria. La prensa afín a los sectores obreros comenzó a valorar el desarrollo industrial y comercial de la ciudad de Concepción, destacando los logros obtenidos:

La industria i comercio locales han tomado una marcha progresiva del todo consoladora, augurando para Concepción un desarrollo no lejano que la colocará en un rango prominente i envidiable con respecto a las otras ciudades de la República. ${ }^{46}$

Para el redactor del artículo, el desarrollo de la «industria i comercio» le deparaba a la ciudad un seguro progreso. Resulta sintomático que para consolidar esta tan auspiciosa etapa, la población demandara con vehemencia la presencia coercitiva del Estado con el propósito de darles «seguridad»:

La población, por su parte, reclama mayor vigilancia, más seguridad. ¿Cómo concederlas si los guardianes son reducidos? Los barrios apartados que son siempre los focos perennes de desórdenes, son los que exijen con mayor anhelo la policía[...]Nuestro pueblo es tranquilo i timorato a más de honrado[...] La humanidad i el interés de la ciudad exijen el aumento de la policía[...] El interés de la ciudad exije también el aumento para su mayor seguridad i vigilancia, para que cada cual descanse tranquilo viendo su propiedad a salvo del ataque de injustos agresores[...] en una palabra, el aumento de la policía es una necesidad. ${ }^{47}$

La cita presentada no era una excepción, más bien fue la regla en la prensa penquista. El periódico «La democracia», de donde fue extraído el comentario, no representaba la postura oficialista, al contrario, se autodefinía como un periódico «comercial, político y social»; por lo tanto, puede considerarse, con cierto grado de certeza, un portavoz de las aspiraciones de la población. Por ende, las demandas de los grupos subalternos urbanos dan cuenta de los cambios ocurridos en el contenido de su economía moral.

Las protestas sociales adquirieron distintas formas entre los sectores subalternos, quedando reflejado en el trasfondo de la cita reseñada más arriba. Llama la atención que la mayoría de las situaciones visibles de conflicto cotidiano se produjesen entre integrantes de las clases más necesitadas. Principalmente era una conflictividad intraclases. Queda en evidencia, entonces, que los discursos dominantes fueron apropiados por una mayoría de la población urbana, pero hubo espacios periféricos (por ejemplo el barrio de «Aguas negras», localizado en el límite oriental de la ciudad)

46 ANCh, La democracia, Concepción, sábado 9 de agosto de 1873, 2.

47 Idem. 
donde no fueron legitimados ni adoptados. Esta actitud de rebeldía, por parte de grupos que habitaban en esos lugares, da cuenta de la presencia de espacios culturales residuales que se manifestaban rechazando la implantación de normas de control social de tipo gubernativo. Asimismo, puede ser expresión del malestar por no poder disfrutar de los beneficios de un sistema que generaba marginación. Dejamos sólo enunciados estos aspectos que podrían ser abordados en futuros estudios.

La legitimación de los mecanismos de control ejercidos por los grupos de poder, provocó una fragmentación en la economía moral de la población subalterna. Aquella mayoría de la población urbana que se apropió de los discursos hegemónicos plasmados en la institucionalidad estatal, asumió una visión de las relaciones sociales de manera diferente a aquella porción de población subalterna que deslegitimó tales directrices. Como consecuencia se llevó a cabo una confrontación de culturas legales dentro de los mismos sectores subalternos, entendiendo por este término el modo como los distintos grupos sociales percibían la ley. Se produjo una disociación de visiones de mundo entre integrantes de la sociedad civil llegando a la paradoja de replicar formas de represión, que también podían ser ejercidas hacia ellos, contra sujetos insubordinados de su propio sector. A medida que se entronizó la idea de ganancia y propiedad privada exclusiva el papel asignado a la policía, en cuanto garante del orden social, fue en aumento. Ya hacia 1860 se expresaba esta idea:

Es indudable que nuestras policías, como las de todo el mundo, son las que más contribuyen al mantenimiento del orden público, al respeto de la propiedad i a la aprehensión i castigo de los malhechores que infestan las ciudades. Pero no basta dictar disposiciones, si estas no deben ser cumplidas con toda exactitud; de su exacto cumplimiento depende en gran parte, por no decir en el todo, la buena marcha de la cosa pública, el aseo, y todo cuanto es inherente a una policía organizada. ${ }^{48}$

En el ámbito político, los contenidos de conciencia de la población también se vieron modificados debido a la concordancia e influencia entre algunos postulados de las elites liberales y los partidos de tendencia socialista. Durante los primeros años de la década de 1870, estos últimos llamaban al pueblo a congregarse en reuniones públicas — «meeting»- con el objetivo de expresar sus opiniones políticas. Encendidas convocatorias se hacían sentir en estos términos:

48 ANCh, El Correo del Sur, Concepción, martes 19 de junio de 1860, 1. 
El «meeting» del domingo ha manifestado lo que pueden los hijos de Concepción, cuando se trata de acentuar sus ideas i lo que quieren en la solución de las cuestiones que la libertad ajita en estos momentos. Los ciudadanos más esclarecidos, los campeones de la idea liberal de este pueblo con ese acento firme i sonoro[...] hicieron estremecerse el corazón de la hermosa concurrencia[...] Desde la fecha de nuestra emancipación política hasta el presente sólo hemos tenido palabras de queja i de dureza para con los conductores de la nación tratándose de libertades; mas ya que otros han iniciado i afianzado la felicidad material; ya que la iniciativa individual[...] está al frente del desarrollo comercial e industrial; ya que una paz estable ha traído al pueblo el cariño, el trabajo i hábitos de orden. ${ }^{49}$

Las manifestaciones políticas masivas, como las que narra el texto citado, invitaban a distintos sectores de la sociedad penquista a la participación cívica. La estrategia liberal de incorporar a los actores sociales a través de políticas inclusivas, fue parte de una efectiva retórica persuasiva dirigida a quienes hasta no pocos años atrás habían sido expresamente excluidos de la vida política. En esos «meeting», no sólo se lograba un efecto de masas, sino también se concretaba una labor pedagógica donde el adoctrinamiento ideológico cumplía un rol central:

Jamás el pueblo de Concepción había presenciado una manifestación tan espléndida como la del domingo. Convocados todos los ciudadanos para enviar un voto de confianza i aliento al gobierno que trabaja ahora por el bien del país, no se hicieron esperar a tan santo llamado, i la hora prefijada para la reunión, el teatro se veía completamente invadido de buenos ciudadanos[...] Una concurrencia de mil quinientas personas $[. .$.$] esta numerosa concurrencia paseándose por la plaza para ser contempla-$ dos de todos i de todo su número contado, indican que Concepción ha muerto su indolencia i se presenta, con sus nobles antecedentes, a la vida activa, con fe en el porvenir, con la esperanza en el corazón..$^{50}$

La economía moral del sector de la población urbana que hizo propio el discurso liberal, se modificó. Ello implicó el reemplazo de la antigua economía doméstica por otra basada en el cálculo y la competencia por la ganancia. Al producirse esta transformación en las clases subalternas, las protestas sociales que se llevaron a efecto en el último tercio del siglo XIX estuvieron mediatizadas por este sustrato cultural. ${ }^{51}$

49 ANCh, La democracia, Concepción, 28 de octubre de 1874, 2. Cabe destacar el hecho que estas masivas reuniones políticas se insertan en un clima de ampliación del electorado, que verá la luz de manera efectiva con la «Ley electoral de 1874». Joignant, 81, 2001, 245-275.

50 ANCh, La democracia, Concepción, 28 de octubre de 1874, 2.

51 Esto es lo que E.P. Thompson ha descubierto en los contenidos de los motines de subsistencia y las protestas campesinas en la Inglaterra del siglo XVIII. Cfr.: Aguirre Rojas, 2010, 196. 
La «paradoja de la represión», a la cual hemos hecho alusión, se explica por este cambio en la economía moral de la población. Una vez que los sectores subalternos llevaron a cabo el proceso de deslegitimación de sus propios contenidos de conciencia reemplazándolos por aquellos que habían legitimado, provenientes de los grupos dominantes, la antigua tensión del choque cultural entre ambos sectores se tornó difusa. Ahora el conflicto se trasladará al interior de la sociedad civil. La conflictividad se evidenciará entre miembros de un mismo sector que, producto del triunfo de los postulados elitarios, se dividirán en cuanto a sus visiones de mundo. Producto del cambio en los contenidos de la economía moral ya no se reconocerán como partícipes de posturas afines, sino que asumirán una estructura antagónica que reproducirá el esquema de dominación y hegemonía utilizado por las elites.

En la concepción gramsciana clásica, la hegemonía es entendida como una estrategia de adquisición del consentimiento activo de las masas mediante su auto-organización a partir de la sociedad civil y los aparatos de hegemonía (fábrica, escuela o familia). ${ }^{52}$ En la ciudad de Concepción esto fue efectivo una vez que el doble proceso de deslegitimación y legitimación se hubo realizado.

Los barrios de menores recursos de Concepción generalmente coincidieron con los límites de la ciudad. Varios de ellos eran espacios conflictivos, pero esa conflictividad al ser historiada nos proporciona una muestra de la progresión de los postulados hegemónicos en la sociedad civil durante la segunda mitad del siglo XIX. En 1860 era conocido como territorio riesgoso el barrio del «Agua Negra», ubicado en el límite oriental de la ciudad de Concepción en las cercanías del río Andalién. En ese lugar se refugiaban distintos tipos de personas que transgredían la ley, muchas veces amparados por los habitantes del sector. La policía, por lo general, no entraba en ese barrio, pues era un territorio peligroso para quienes no eran residentes o no tenían vínculos con sus habitantes. ${ }^{53}$ Otros barrios con

52 Galindo Cáceres, 1992, 55.

53 A modo de ejemplo, algunas noticias de ese barrio: Uno de los individuos que se ocupa de tocar por las calles el organito, cuyo nombre no nos ha sido posible averiguar, el sábado andaba ejerciendo su profesión a las ocho i media de la noche, cerca del «Agua Negra». En el camino encontró cuatro hombres que... lo molieron a palos, golpes que hasta ahora han puesto en peligro la vida de este desgraciado. ANCh, El Correo del Sur, Concepción, 15 de mayo de 1860, 3. Sin que el guardia le hubiese ordenado hacer alto, en fin sin causa alguna...le disparó un tiro de pistola con bala i en seguida dio inmediatamente carrera a su caballo, dirijiéndose hacia el «Agua Negra». Idem. Se nos refiere que el domingo en la noche tuvo uno lugar [salteo] en el «Agua Negra»; i no ha sido poco el atrevimiento de los ladrones, pues se nos asegura que esto sucedía a las nueve de la noche. Ibídem, 5 de junio de 1860. 
similares características eran «La puntilla» y el «Agua de las niñas», los cuales se localizaban en el límite occidental de la ciudad. Estos barrios, si bien mantuvieron la característica de espacios conflictivos, hacia 1882 comenzaron a evidenciar fisuras dentro de las opiniones de sus habitantes. El periódico «La libertad católica» en una noticia titulada «frecuentes desórdenes» nos ilustra al respecto:

Ocurren especialmente [«frecuentes desórdenes»] los días domingos, en el barrio de la Puntilla, o sea desde el cuartel que lleva ese nombre hasta el Agua de las Niñas. La policía de Concepción no alcanza para esos barrios i el orden debe allí ser guardado por los mismos vecinos que se turnan semanalmente en el cargo de celadores[...] Varios buenos vecinos de ese barrio como también de la avenida de Arturo Prat, donde sucede igual cosa, nos han suplicado que pidamos al señor Comandante de Policía que ordenen que algún policial de a caballo haga sus frecuentes paseos en aquellos puntos los días domingos, i que ojalá se situasen por allí siquiera desde el medio día en adelante..$^{54}$

Como se puede observar, los mecanismos de represión fueron expansivos. Los patrones de conducta y los principios del orden social, impuestos por los grupos dominantes en la tan anhelada búsqueda del «progreso» material del Estado, no sólo fueron adoptados sino también defendidos por los sujetos subalternos. Eso explica la presencia de «vecinos celadores» como una fórmula de control social utilizada por algunos barrios ante la insuficiente dotación policial en áreas periféricas de Concepción. Incluso se le confiere un aspecto valórico y de legitimidad a dicho control, pues quienes «suplicaban» por la presencia policial eran catalogados como «buenos vecinos».

Con la transformación de la economía moral de la población podemos establecer que la hegemonía del Estado oligárquico liberal se construyó en Concepción a partir de una concesión que hizo la sociedad civil al Estado, dentro del Estado. Hubo un período relativamente corto, que identificamos entre 1850 y 1880 , de apropiación y legitimación de los postulados liberales. A este proceso contribuyeron varios discursos persuasivos, donde la idea del progreso material sobre la base de la educación fue uno de los que presentó mayores consensos.

54 ANCh, La libertad católica, Concepción, 23 de agosto de 1882, 2. 


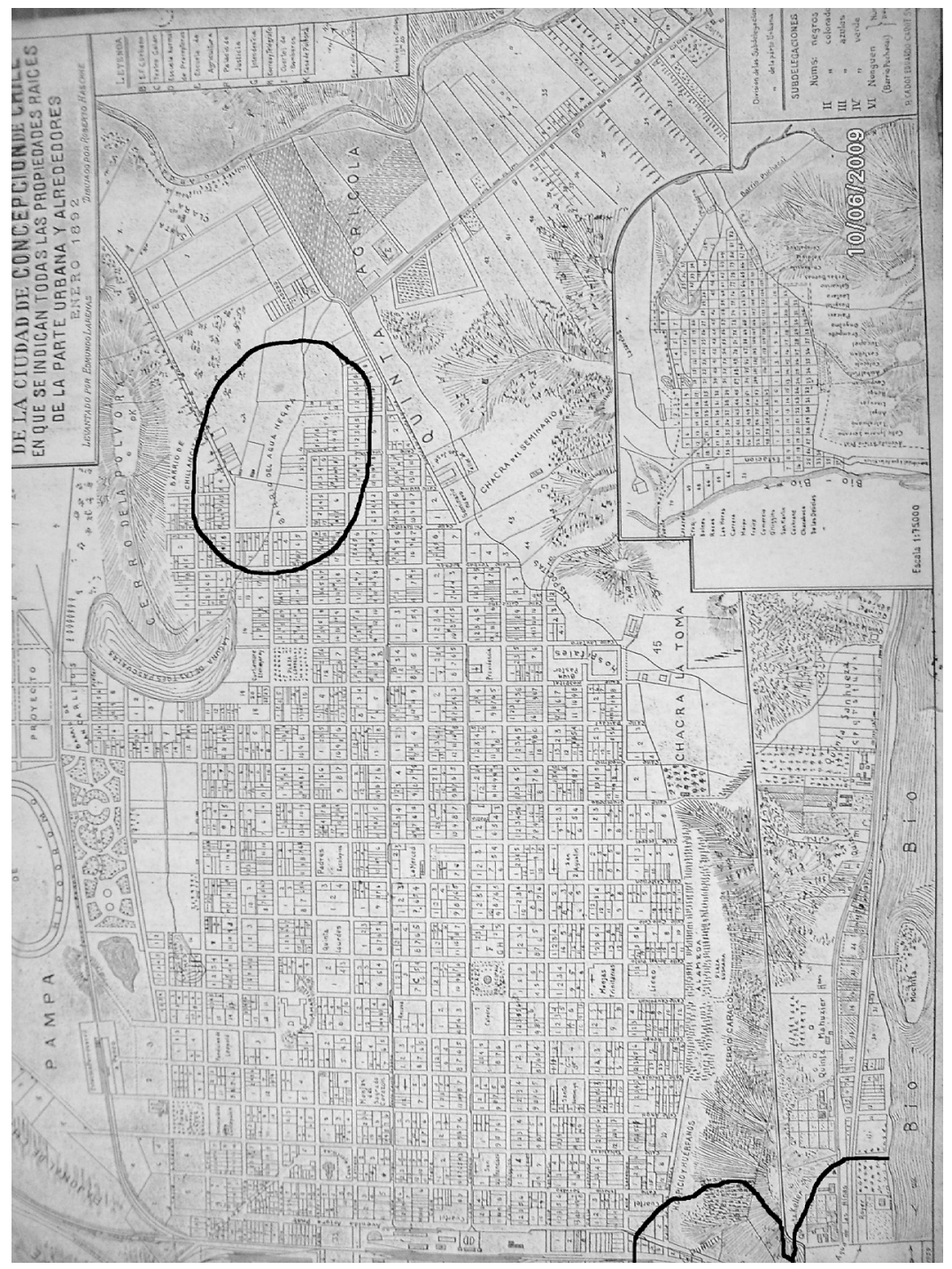




\section{Educación y Habitus}

La «violencia simbólica» implica la imposición de la cultura dominante a los grupos subalternos, siendo una de sus agencias más relevantes la educación. ${ }^{55} \mathrm{~A}$ tal punto resulta la introyección llevada a cabo por el sistema educacional, que los postulados hegemónicos no sólo logran ser reconocidos por los sectores subalternos sino que también éstos llegan a reconocerse en ellos.

En la ciudad de Concepción se esgrimía que la educación era el mecanismo fundamental para lograr el tan deseado bienestar social y progreso económico. Si en la década de 1860 el rol protagónico para alcanzar el desarrollo social, a través del orden, fue adjudicado los tribunales de justicia y la policía, en la de 1870 no hubo sector político y social que no adjudicara esta cualidad al sistema educacional.

Un artículo escrito en 1870, con una mirada optimista del acontecer nacional, indicaba que:

En Chile, la agricultura, la cultura i la civilización están colocadas a la vanguardia de los otros países de nuestro continente. ${ }^{56}$

El articulista, reconociendo este nuevo escenario de progreso, consideraba que estaría incompleto en tanto el «obrero» no participase de la estructura modernizadora que había abrazado el Estado:

[...] a la vuelta de algún tiempo esta misma industria vendrá a ser del dominio público i el obrero chileno se abrá apoderado de un arte para el cual no está preparado por la absoluta carencia de los conocimientos que se necesitan para un desempeño acertado[...] Pero al intentarlo, no queremos hacer estensivo nuestro estudio a toda la clase obrera de nuestro país, sino solamente al pueblo de Concepción i demostrar el atraso en que se encuentra por la falta de instrucción e indicar cual sea el remedio para cortar tan grave mal. ${ }^{57}$

Una descripción del estado de las escuelas en la provincia de Concepción, a mediados de 1858, permite apreciar que hasta esa fecha la educación no era una prioridad de las autoridades. En el informe evacuado por el «visitador» de los establecimientos educacionales se indicaba que en el departamento de Concepción había siete escuelas diurnas para niños y una nocturna para adultos. Asimismo, el funcionario lamentaba que:

55 Burke, 1997, 103-104.

56 ANCh, El alba, Concepción, 16 de octubre de 1870, 1.

57 Ibídem 
El estado de estas escuelas cuando practiqué la visita, no me fue nada satisfactorio, porque casi en ninguna de ellas se notaba la menor organización. La uniformidad en los métodos de enseñanza era desconocida, como también lo que constituye un buen réjimen interior[...] La distribución del tiempo era viciosa, porque cada preceptor la determinaba como mejor le parecía o lo estimaba conveniente. ${ }^{58}$

Ante este diagnóstico tan poco halagüeño, el enviado del gobierno precisó en su informe:

Puedo asegurar que solo ahora se de principio para ponerlas a la altura que el Supremo Gobierno anhela con tanto interés i al decidido empeño que con este mismo fin coopera el señor Intendente de esta provincia. ${ }^{59}$

Efectivamente, el énfasis puesto en el desarrollo del sistema educacional tuvo eco en los sectores populares que consideraron un derecho cívico el gozar de un mejoramiento en las condiciones educativas. A comienzos de la década de 1870 la visión de Concepción como una sociedad en progreso era evidente. El desarrollo industrial se presentaba auspicioso, al igual que el plano educativo; en tanto, a diferencia de décadas anteriores, fue el sistema judicial el que recibió las mayores críticas por su mal funcionamiento:

Es innegable que seguimos una senda progresiva. Concepción se encuentra a alguna altura... La industria avanza, la instrucción también, solo la administración de la justicia permanece floja, sin actividad. ${ }^{60}$

Si bien hubo quejas en la provincia que apuntaban a la inoperancia de las autoridades locales en cuanto a implementar ciertas políticas educacionales provenientes del gobierno central como era la instalación de «Comisiones visitadoras de escuelas», ${ }^{61}$ la educación siguió siendo vista como un factor de desarrollo por todos los sectores sociales. Los grupos subalternos vieron en la «Sociedad Popular de Educación» un instrumento de mejoramiento social, ya que era estimada como una instancia para salir de la condición de desmedro en la que se encontraban:

La obra es grande, pero los obreros también aumentan, se alistan a porfía i no vemos el momento en que los cimientos arrojados por la juventud se conviertan en brillante edificio; orgullo de Concepción, bienestar de la república...Las sociedades de

58 ANCh, El Monitor de las Escuelas Primarias, Santiago de Chile, 15 de marzo de 1859, 21.

59 Ibídem.

60 ANCh, La democracia, Concepción, 4 de junio de 1873, 2.

61 ANCh, La democracia, Concepción, 18 de junio de 1873, 2. 
educación surjen, la juventud los patrocina con entusiasmo, la madurez con alegría, el obrero alza la vista i contempla con rostro radiante la nueva esperanza que alienta y anima su corazón. ${ }^{62}$

Se perfila en estos comentarios el nuevo papel autoasignado por los sectores subalternos urbanos. Las relaciones sociales que se establecen en el ámbito de la ciudad van incubando una nueva forma de entender las estructuras económicas y políticas de la población. Cuando los vínculos de dependencia de la economía doméstica fueron reemplazados por la relación contractual, de tipo impersonal, entonces la población subalterna se confirió la posibilidad del autoaprendizaje político.

El nuevo escenario urbano, con toda una arquitectura discursiva liberal, fue el ambiente adecuado para que la apropiación de estos postulados produjese un efecto no esperado por las elites: la conversión del sujeto subalterno no sólo en un «ser moral» sino también en un «ser político». A través de la elección del liberalismo los grupos dominantes aspiraban lograr el desarrollo económico. Paralelamente, la misma estrategia trajo como correlato que la población se inspirase en aquellos ideales para obtener una mejor posición en la estructura social. Esto no fue bien visto por los grupos dominantes en Concepción quienes se opusieron a estas intenciones de los sectores populares. De esta forma se explica la molestia expresada por estos últimos en las denuncias de intentos de boicot al desarrollo educacional que se estaba produciendo:

A pesar de la limpieza con que se trata de llevar a feliz término la realización de la obra, algunos satélites del mal, con su torcida voluntad, hacen lo posible para mostrar manchas donde ni siquiera se divisan[...] ¿Acaso no podrán soportar que la luz arranque el cetro a las tinieblas? Acaso su egoísmo las arrastra hasta vituperar brillantes tendencias, laudables propósitos?

La afinidad entre los discursos elitarios y la visión subalterna referida al mejoramiento económico sumada a una estrategia de desarrollo que posibilitaba la participación, permitió que se pudiese construir la hegemonía estatal sobre la base de la ideología liberal. Los mecanismos de control y difusión de las ideas dominantes, como la policía y la educación, posibilitaron que la «negociación» entre los grupos hegemónicos y subalternos se estableciera bajo nuevas formas de relaciones sociales. De esta manera, el poder simbólico estatal se fue estructurando con la venia de los sujetos

62 ANCh, La democracia, Concepción, 24 de abril de 1872, 2. 
subalternos. Dicho poder permanecería estable siempre y cuando la oligarquía permitiese a los grupos subalternos participar de espacios políticos y mejoras sociales que estuviesen de acuerdo a los criterios contenidos en la economía moral de la población. Si ello no ocurriese, acarrearía la deslegitimación de los grupos dominantes y, en consecuencia, devendría la alteración del orden social. Así fue entendido por una de las mentes más perceptivas de la elite santiaguina, Julio Menadier, editor del «Boletín» de la Sociedad Nacional de Agricultura, quien en 1883 no sólo proporcionó un diagnóstico de las razones del malestar de la población subalterna, sino también concluyó con una propuesta que sirve como corolario a la estrategia liberal del control social:

La mayor prosperidad de una gran parte de la nación revelada por el lujo i ostentación, se ve irremediablemente acompañada también, doquiera, por la mayor miseria o desgracia de otra facción, la cual no tarda en solicitar de aquella los socorros para subsistir...Mientras no se facilite la instrucción, el amor al trabajo i el espíritu de economía, todas las medidas tomadas contra los vagos han de quedar verdaderos «golpes en vago»[...] Dando ocupación remunerativa a la masa del pueblo, se quitó su malestar habitual i se incrementó las fuerzas productoras i con ellas los consumidores. ${ }^{63}$

\section{Conclusiones}

Durante el siglo XIX, las élites dirigentes de la provincia y ciudad de Concepción se abocaron a la tarea de organizar un Estado republicano utilizando diversos mecanismos de control social. En la etapa inmediatamente posterior a la guerra de independencia las tendencias liberales no lograron consolidar la gobernabilidad en Chile (1820-1829). De hecho, fue un período finalizado abruptamente por un golpe de Estado llevado a cabo por la reacción conservadora que instaló un modelo coercitivo-estatal de control social (1830-1860). Hacia fines del período conservador las élites chilenas sufrieron un giro en sus postulados y fueron transitando hacia el liberalismo producto de las tendencias políticas y económicas de la época, provenientes principalmente de Europa.

La estrategia liberal establecía ciertas condiciones básicas para que el modelo funcionase, en función del progreso material. Una de ellas era el orden social. Este concepto no se limitaba sólo al obedecimiento de ciertas normas legales (control social punitivo), sino que implicaba la necesaria

63 ANCh, Boletín, Santiago, Sociedad Nacional de Agricultura, 5 de diciembre de 1883, 97-98. 
transformación de los contenidos de conciencia de la población subalterna. Lo imperioso era transformar a las «clases peligrosas» en «seres morales». De esta manera, la «civilización de las costumbres» de los sectores subalternos se convirtió en la meta impuesta por las elites decimonónicas tanto del país como de Concepción. El punto de inflexión de este proceso fue el año 1860. Durante el mes de enero de ese año, y como parte de la reestructuración de los cuerpos de policía, se creó la policía urbana la que, a partir de entonces, funcionó en paralelo a la policía de seguridad. La primera tenía una labor coercitiva; en cambio, la segunda, se dedicó a la vigilancia del aseo, ornato e higiene de la ciudad. Este hecho inauguró la estrategia de control social por el consenso, ya que se fueron inculcando de manera sistemática modos de comportamientos ajenos a los que tradicionalmente la población practicaba.

Hacia 1870 las elites dirigentes estimaron a bien adoptar el modelo liberal de desarrollo, lo cual exigía que la población ya no sólo cambiase sus estilos de vida sino que, además, debían incorporarse a la cultura liberal. Ello implicaba que valores propios del liberalismo tales como el orden, la sistematicidad laboral, la regulación del tiempo y el valor del salario, debían ser adoptados por la cultura subalterna. El ambiente de la ciudad fue propicio para el logro de estos cambios. Fue en ella donde las ideas y discursos provenientes de Europa y Estados Unidos calaron rápidamente en la mentalidad de los obreros. Una de estas transformaciones tuvo que ver con la idea del trabajo. Hacia la década de 1830 la legislación lo aplicaba como castigo a quienes no se sujetaban a las normativas legales de la época, situación que variará hacia fines del siglo XIX cuando la población subalterna lo entenderá como un derecho que debía ser protegido y valorado. Se estimaba que mediante el trabajo sistemático se podían alcanzar niveles de desarrollo propicios para la población.

De manera transversal, tanto las élites como los grupos subalternos concordaron en que mediante la actividad laboral se podía conseguir el progreso material y social. Similar visión tuvieron ambos grupos acerca de la educación. Ésta era entendida como la base para el mejoramiento de las condiciones de vida y el alejamiento de los «males» de la comunidad. La concordancia entre los postulados de los discursos de la elite y la población subalterna da cuenta de un doble proceso llevado a cabo por esta última: a) la apropiación y legitimación de los discursos hegemónicos, y b) la deslegitimación de los propios. Cuando esto se produjo, los sectores subalternos lograron concebir al Estado como una institución en la cual ellos 
también podían participar e influir. Le concedieron legitimidad. Y, con ello, colaboraron al establecimiento del poder hegemónico.

El equilibrio de las relaciones entre los sectores dominantes y subalternos duraría hasta que aquellas nociones legitimizantes, que sustentaban la hegemonía estatal, llegasen a ser percibidas por la población como transgredidas. En ese momento, el poder oligárquico estatal caería en la ilegitimidad, tal como ocurrió con la crisis de comienzos del siglo XX.

\section{Fuentes}

Boletín, Santiago, Sociedad Nacional de Agricultura, 5 de diciembre de 1883.

Boletín de las leyes y decretos del Gobierno, «Ordenanza municipal de Concepción», Libro XXVIII, Santiago, 2 de enero de 1860.

Boletín de las leyes y decretos del Gobierno, «Ordenanza de policía para la ciudad de Concepción», Libro LIV, 7, Santiago, 10 de agosto de 1885.

El alba, Concepción, 16 de octubre de 1870.

El Correo del Sur, Concepción, 6 de octubre de 1860.

El Correo del Sur, Concepción, 18 de noviembre de 1852.

El Correo del Sur, Concepción, 25 de diciembre de 1852.

El Correo del Sur, Concepción, martes 19 de junio de 1860.

El faro de Bío-Bío, «Reglamento de Policía de Concepción», Concepción, miércoles 29 de enero de 1834 .

El Monitor de las Escuelas Primarias, Santiago de Chile, 15 de marzo de 1859.

La democracia, Concepción, 18 de junio de 1873.

La democracia, Concepción, 24 de abril de 1872.

La democracia, Concepción, 28 de octubre de 1874.

La democracia, Concepción, 4 de junio de 1873.

La democracia, Concepción, sábado 9 de agosto de 1873.

La libertad católica, Concepción, 23 de agosto de 1882.

Plano de la ciudad de Concepción, 1892.

\section{Bibliografía}

Aguirre Rojas, Carlos: De Carlos Marx a Immanuel Wallerstein, Santiago, Ediciones Universidad Católica Silva Henríquez, 2010.

Araya, Alejandra: Ociosos, vagabundos y malentretenidos en Chile Colonial, Santiago, DIBAM, 1999. 
Bourdieu, Pierre: Las estructuras sociales de la economía, Buenos Aires, Manantial, 2005.

Burke, Peter: Historia y Teoría social, México, Instituto Mora, 1997.

Carmagnani, Marcello: Los mecanismos de la vida económica en una sociedad colonial. Chile 1680-1830, Santiago, DIBAM, 2001.

Carvallo Goyeneche, Vicente: Descripción Histórico-Geográfica del Reyno de Chile, Tomo X, Santiago, Imprenta de la Librería del Mercurio, 1876.

Cavieres, Eduardo: Comercio chileno y comerciantes ingleses 1820-1880: un ciclo de historia económica, Valparaíso, Universidad Católica de Valparaíso, 1988.

Cos Iriberri, José: Memoria de 1799, citado en Miguel Cruchaga, Estudio sobre organización económica y la hacienda pública de Chile, Tomo III, Madrid, 1929.

Fernández Undurraga, Diego: Vida jurídica práctica contenida en los Archivos de Escribanos del siglo XVIII, Memoria de prueba para optar al grado de Licenciado en Ciencia Jurídicas y Sociales, Facultad de Derecho, Universidad de Chile, Santiago, 1989.

Galindo Cáceres, Jesús: Ideología y comunicación. México, Premia editora de libros, 1992.

Guha, Ranajit: Dominance without Hegemony, Cambridge, Harvard University Press, 1997.

Hall, Stuart: «Old and New Identities, Old an New Ethnicities», en King, Anthony (ed.), Culture, Globalisation and the Worl-System: Contemporary Conditions for the Representation of Identity, Minneapolis, University of Minnesota, 1997, 31-68.

Heise González, Julio: 150 años de evolución institucional, Santiago, Editorial Andrés Bello, 2007.

Joignant, Alfredo: «El lugar del voto. La ley electoral de 1874 y la invención del ciudadano-elector en Chile», Revista de Estudios Públicos, 81, Santiago, Centro de Estudios Públicos, 2001, 245-275.

León, Marco: Sistema carcelario en Chile. Visiones, realidades y proyectos (18161916), Santiago, DIBAM, 1996.

Méndez, Luz María: La exportación minera en Chile, 1800-1840, Santiago, Editorial Universitaria, 2004.

Orozco, José: «La construcción de la hegemonía en la definición del valor en el arte popular», Portal Iberoamericano de Gestión Cultural, Boletín de Gestión Cultural [en línea].12 (2005). Disponible en:

http://www.gestioncultural.org/gc/boletin/pdf/bgc12-JLMariscal.pdf

Ortega, Luis: Chile en ruta al capitalismo. Cambio, euforia y depresión, 18501880, Santiago, DIBAM, 2005.

Portales, Diego: «Administración de justicia criminal», El Mercurio de Valparaíso, Valparaíso, 17 de enero de 1832, 4. 
Rodríguez, Ileana: «Hegemonía y dominio: subalternidad, un significado flotante», en Castro-Gómez, Santiago y Mendieta, Eduardo (eds.), Teorías sin disciplina, México, Miguel Ángel Porrúa, 1998, 84-102.

Rojas Gómez, Mauricio: «Aspectos económicos relacionados con el delito de abigeato en la provincia de Concepción, 1820-1850», Revista Cuadernos de Historia, 26 Santiago, 2007a, 32-73.

Rojas Gómez, Mauricio: «Entre la legitimidad y la criminalidad: el caso del "Aparaguayamiento" en Concepción, 1800-1850», Historia, 40/2, Santiago, 2007b, 419-444.

Rojas Gómez, Mauricio: «La creación de la policía rural como medio de control social en las provincias de Concepción y Ñuble en la segunda mitad del siglo XIX», en Cáceres, Juan (ed.), Experiencias de historia regional en Chile, Valparaíso, Universidad Católica de Valparaíso, 2008a, 28-52.

Rojas Gómez, Mauricio: Las voces de la justicia. Delito y sociedad en Concepción (1820-1875). Santiago, DIBAM, 2008b.

Rojas Gómez, Mauricio: «La ciudad como agente moralizador: la policía y la ciudad de Concepción (Chile), 1850-1880», Historia, 44/2, Santiago, 2011, 443-465.

Romano, Ruggiero: Mecanismo y elementos del sistema económico colonial americano. Siglo XVI-XVIII, México, Fondo de Cultura Económica, 2004.

Salazar, Gabriel: Labradores, peones y proletarios, Santiago, LOM, 2000.

Salazar, Gabriel; Pinto, Julio: Historia contemporánea de Chile. La economía: mercados, empresarios y trabajadores. Tomo III. Santiago, LOM, 2002.

Salazar, Gabriel: Ser niño «huacho» en la historia de Chile (siglo XIX), Santiago, LOM, 2006.

Salazar, Gabriel: Mercaderes, empresarios y capitalistas (Chile, siglo XIX), Santiago, Editorial Sudamericana, 2009.

Scardaville, Michael C.: «(Hapsburg) Law and (Bourbon) Order: State Authority, Popular Unrest, and the Criminal Justice System im Bourbon Mexico City», en Aguirre, Carlos y Buffington, Robert (eds.), Reconstructing Criminality in Latin America, Wilmington, Jaguar Books, 2000, 47-81.

Sombart, Werner: El burgués, Madrid, Alianza Universidad, 1972.

Thompson, E. P.: Costumbres en común, Barcelona, Crítica, 2000.

Villalobos, Sergio: El comercio y la crisis colonial, Santiago, Akhilleus, 2009. 